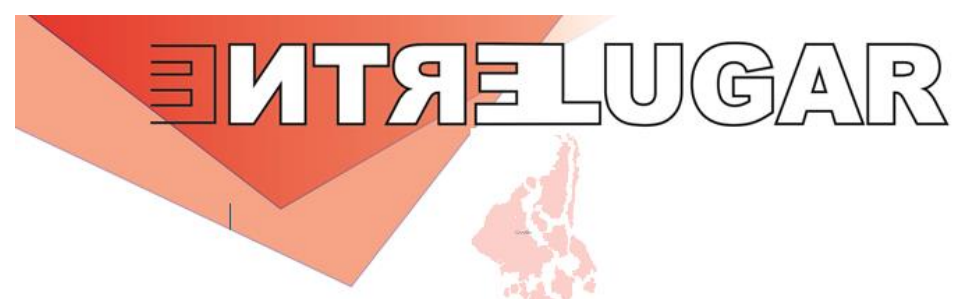

\title{
RESENHA: A CIDADE NO SÉCULO XXI: SEGREGAÇÃO E BANALIZAÇÃO DO ESPAÇO
}

\author{
Anderson Aparecido Santos da Silva \\ andersonaparecido52@gmail.com \\ Universidade Federal da Grande Dourados
}

O livro "A cidade no século XXI - Segregação e banalização do espaço" foi escrito pelo geógrafo e Professor Alvaro Ferreira, que é graduado em Geografia pela Universidade Estadual do Rio de Janeiro (UERJ), possui mestrado em Planejamento Urbano e Regional pela IPPUR, na Universidade Federal do Rio de Janeiro (UFRJ), e doutorado na Universidade de São Paulo (USP), além de Pós Doutorado pela Universidade de Barcelona, sob a orientação de Horacio Capel.

Alvaro Ferreira é pesquisador do Programa de Pós Graduação em Geografia da Pontifícia Universidade Católica do Rio de Janeiro (PUC - RIO), professor adjunto da Universidade Estadual do Rio de Janeiro (UERJ), local onde coordenada o Núcleo de Estudos e Pesquisa em Espaço e Metropolização (NEPEM) e o Núcleo Interdisciplinar de Estudos do Espaço da Baixada Fluminense (NIESBF), e atua como colaborador do Núcleo de estudos de Geografia Fluminense (NEGEF).

O livro objeto desta resenha é resultado de estudos e discussões realizadas nos grupos de pesquisa coordenados pelo autor. O livro em questão já está em sua segunda edição, lançada em 2013, que traz algumas atualizações pertinentes acerca da produção do espaço urbano, tendo como objeto o município do Rio de Janeiro, com destaque para projetos de revitalização da cidade para atender a demanda turística de dois grandes eventos, a Copa do Mundo de 2014 e as Olímpiadas realizadas na cidade em 2016.

No capítulo 1, intitulado "A reestruturação produtiva e suas implicações nas cidades" o autor discute a reestruturação produtiva que a cidade do Rio de Janeiro vem passando ao longo de sua história, inter-relacionando aspectos da morfologia da cidade,

\footnotetext{
${ }^{1}$ Graduando do curso de bacharelado em Geografia. Bolsista do Programa de Educação Tutorial de Geografia, PETGeografia.
} 
processos históricos e políticos/econômicos, que transformaram uma cidade, a qual tinha uma economia baseada na produção industrial, e passou a ter uma economia baseada no turismo e na prestação de serviços. A cidade do Rio de Janeiro assim passa a ser planejada e produzida não para atender a necessidade de seus cidadãos, mas sim para atender os anseios e necessidades dos turistas e de grandes empresas, e, investidores internacionais.

Ao longo do capitulo 1, o autor demonstra, por meio do resgate de processos históricos, que os planos de reestruturação da zona portuária e das áreas centrais do Rio de Janeiro, executados anteriormente, excluíram os moradores mais pobres destas áreas; deixa claro que estes planos de reestruturação criaram uma nova forma espacial para a cidade, aprofundando ainda mais a desigualdade socioespacial da cidade. Uma consequência direta da segregação gerada por estas obras é a obrigação dos antigos moradores destas áreas se mudarem para lugares mais afastados e longe dos seus locais de emprego.

O capítulo 2, intitulado de "Políticas de desenvolvimento urbano e mudanças nas formas de administração urbana", o autor faz uma discussão sobre o modo de se pensar e produzir a cidade, e usa como mote a ideia e o ideário do marketing, explicitando como a cidade do Rio de Janeiro passa a ser estruturada como um produto a ser comercializado. Demonstra como setores ligados ao marketing, ao turismo, e, em especial, ao setor hoteleiro, contaram com o apoio e a participação do Estado em diversos níveis (governos Municipal, Estadual e Federal); destaca como foram importantes agentes que direcionaram os rumos dos projetos de revitalização da zona portuária e da área central para a Copa do Mundo e as Olímpiadas. Enfatiza a exclusão dos cidadãos, dos moradores da cidade, das discussões. O autor usa o termo "city marketing" para enfatizar como os agentes majoritários envolvidos na reestruturação urbana da cidade pensam e/ou pensaram a cidade, visando tão apenas a atração de investimentos internacionais, desconsiderando qualquer impacto negativo no âmbito social ou econômico trazidos por estas políticas de produção do espaço urbano.

As “Transformações cada vez mais homogeneizantes nas zonas portuárias das cidades: exemplos para o Rio de Janeiro?", o capítulo 3, faz que o leitor perceba o quanto este tipo de política não é algo novo. O autor traz exemplos de projetos semelhantes 
realizados em cidades ao redor do mundo; as quais também fizeram grandes projetos de revitalizações, nas suas áreas centrais e nas suas zonas portuárias, com o mesmo intuito: atrair grandes investimentos, voltando a sua economia para o turismo e prestação de serviços. Os cinco exemplos demonstrados pelo autor são: as zonas portuárias das cidades Norte Americanas de Boston, Nova York, Miami e Baltimore na década de 1960; a reestruturação da cidade de Barcelona, na Espanha para os jogos Olímpicos de 1992; a revitalização da zona portuária da cidade de Buenos Aires na Argentina no final da década de 1980; e reestruturações de menores impactos realizadas na Austrália, na cidade do Cabo, e, na Nova Zelândia.

A partir destes exemplos, o autor consegue demonstrar características marcantes e convergentes que demonstram um modelo de reestruturação urbana excludente, as quais são:

- todos estes projetos, sejam eles voltados para grandes eventos ou não, tinham a promessa de atrair grandes investimentos e gerar muitos empregos;

- trariam melhorias dos serviços públicos, como transporte, saúde e segurança, não só para os turistas, mas também para os cidadãos e residentes destas cidades;

Todavia, o que se percebe ao se concluir estes projetos, é o inverso. Ao invés de se cumprir o que foi planejado e prometido, esses trouxeram um enorme endividamento para o Estado (governos Municipal, Estadual e Federal), ocasionando crises econômicas, a não atração de investimentos em outros setores e a geração de empregos muito abaixo do esperado. O mais grave: não trouxeram melhorias nos serviços públicos de fato.

Salvo o contexto e realidades das cidades citadas e discutidas pelo autor, cada uma com seu grande projeto, além de não cumprir o prometido trouxe impactos sociais negativos para os seus moradores. O incômodo e o transtorno causado durante as obras e movimento de pessoas para os moradores das zonas portuárias das cidades norte americanas, e a crise econômica do governo espanhol desencadeada pela crise econômica da década de 1990 são exemplos de como projetos de revitalizações de zonas portuárias ou de áreas centrais que foquem somente na atração de investimento internacional, que 
não incluam os seus habitantes para a negociação e planejamento destas revitalizações, tem uma grande tendência ao fracasso, seja por fatores internos e/ou externos.

No quarto e último capítulo do livro, intitulado de "A produção do espaço urbano no Rio de Janeiro: entre projetos de revitalização para a zona portuária e (i)mobilismos", o autor demonstra de maneira inequívoca, explicita, como o envolvimento do setor empresarial, a negociação não realizada entre os moradores e os amplos setores da sociedade envolvidos nos projetos de revitalização da zona portuária e da área central da cidade do Rio da Janeiro para a Copa do Mundo de 2014 e para as Olímpiadas de 2016 trouxeram as mesmas promessas e problemas de outras cidades do mundo, essencialmente aquelas utilizadas nos exemplos do capítulo anterior. E mais, no caso da cidade do Rio de Janeiro o autor demonstra que os projetos foram executados, implementados, de forma vertical, não incluindo e nem ao menos informando os moradores das áreas afetadas.

Em síntese, pode-se afirmar que o livro é de extrema importância para se pensar a produção do espaço urbano e o papel dos agentes envolvidos em sua (re)estruturação, obrigando-nos a pensar o tipo de cidade e espaço urbano que temos, e o tipo de cidade e espaço urbano que queremos. Deixa claro, explicita, os problemas urbanos decorrentes da visão de uma city marketing, um modelo excludente e não exclusivo da cidade do Rio de Janeiro. Ao abordar problemas como segregação urbana, exclusão e marginalização de grupos sociais e étnicos vulneráveis nos permite fazer analogias e analises de outras cidades como São Paulo, Brasília, Goiânia, e, até mesmo em cidades médias como o caso de Dourados.

Por analogia, ao se analisar com cuidado a forma como o Estado (governos Municipal, Estadual e Federal) conduz, induz, a produção do espaço de Dourados (MS), como tratam e olham os Guarani - Kaiowá, podemos evidenciar pontos de convergência. Apesar de suas particularidades históricas e socioespaciais que se manifestam de diferentes maneiras e intensidades, evidenciam os processos de exclusão e segregação, os quais podem até serem muito mais cruéis e perversos. Não há Copa do Mundo; não há Olímpiadas, mas, há o agronegócio. 
Muito mais que um livro de Geografia Urbana, a obra de Alvaro Ferreira revela que as ciências humanas, de maneira geral, tendem a revelar aquilo que se esconde por trás de discursos hegemônicos vindos do Estado e de grandes grupos econômicos, revelando não só as suas contradições como também a face cruel do sistema capitalista, nesse caso escondido em grandes projetos políticos/econômicos voltados não só para as cidades como também para importantes regiões do País.

Lendo esta obra, além de entender as contradições escondidas em tais tipos de projetos, é possível entender o motivo pelo qual, nesse momento histórico, a ciência e o conhecimento produzido pelas universidades públicas estão sendo questionados e atacados, essencialmente aqueles se colocam como críticos e analíticos quanto ao papel do Estado na sociedade. Enquanto houver livros como "A CIDADE NO SÉCULO XXI: SEGREGAÇÃO E BANALIZAÇÃO DO ESPAÇO” haverá uma possibilidade maior das contradições serem reveladas. Talvez seja esse um dos papéis da Geografia enquanto ciência: revelar aquilo que o Estado e grandes grupos econômicos tentam esconder e manipular de forma maniqueísta.

\section{Referência bibliográfica}

FERREIRA, Alvaro. A cidade no século XXI: Segregação e Banalização do Espaço. Rio de Janeiro: Consequência, 2011.

Recebido para publicação em fevereiro de 2020. Aceito para publicação em março de 2020. 